\title{
Comparative effects of glucose and xylose on blood pressure, gastric emptying and incretin hormones in healthy older subjects
}

\author{
Lora Vanis $^{1,2}$, Trygve Hausken ${ }^{3,4}$, Diana Gentilcore ${ }^{1,2}$, Rachael S. Rigda ${ }^{1,2}$, Christopher K. Rayner ${ }^{1,2}$, \\ Christine Feinle-Bisset ${ }^{1,2}$, Michael Horowitz ${ }^{1,2}$ and Karen L. Jones ${ }^{1,2 *}$ \\ ${ }^{1}$ Discipline of Medicine, University of Adelaide, Royal Adelaide Hospital, North Terrace, Adelaide, SA 5000, Australia \\ ${ }^{2}$ NHMRC Centre of Clinical Research Excellence in Nutritional Physiology, Interventions and Outcomes, University of \\ Adelaide, Adelaide, SA 5000, Australia \\ ${ }^{3}$ Institute of Medicine, University of Bergen, Bergen, Norway \\ ${ }^{4}$ National Centre for Ultrasound in Gastroenterology, Haukeland University Hospital, Bergen, Norway
}

(Received 5 July 2010 - Revised 29 November 2010 - Accepted 30 November 2010 - First published online 4 February 2011)

\begin{abstract}
Postprandial hypotension is an important disorder for which current management is suboptimal. In healthy older subjects, oral and smallintestinal glucose administration decreases blood pressure (BP), and the magnitude of the reduction is dependent on the rate of glucose entry into the small intestine and, possibly, the release of glucagon-like peptide-1 (GLP-1). There is little information about the effects of other carbohydrates, particularly those poorly absorbed, on BP. The aim of the present study was to compare the effects of drinks containing xylose, glucose or water alone on BP, gastric emptying (GE), incretin hormone secretion, glycaemia and insulinaemia in healthy older subjects. A total of eight healthy older subjects (aged 65-75 years) had simultaneous measurements of BP (DINAMAP), GE (three-dimensional ultrasound), blood glucose, serum insulin, GLP-1 and glucose-dependent insulinotropic peptide (GIP), on three separate occasions, in a double-blind, randomised order. On each day, subjects consumed a $300 \mathrm{ml}$ drink of water, glucose $(50 \mathrm{~g})$ or D-xylose (50 g). Glucose $(P=0.02)$, but not xylose $(P=0.63)$, was associated with a fall in BP. There was no difference in the GE of glucose and xylose $(P=0.47)$; both emptied slower than water $(P<0 \cdot 001)$. Xylose had minimal effects on blood glucose, serum insulin or serum GIP, but was more potent than glucose in stimulating GLP-1 $(P=0.002)$. In conclusion, in healthy older subjects, xylose empties from the stomach at the same rate as glucose, but has no effect on BP, possibly because it is a potent stimulus for GLP-1 release. Xylose may be considered as an alternative sweetener to glucose in the management of postprandial hypotension.
\end{abstract}

Key words: Ageing: Postprandial hypotension: Ultrasound: Monosaccharides: Glucagon-like peptide-1: Glucose-dependent insulinotropic peptide: Insulin

Postprandial hypotension (PPH), defined as a fall in systolic blood pressure $(\mathrm{BP}) \geq 20 \mathrm{mmHg}$ within $2 \mathrm{~h}$ of a meal ${ }^{(1)}$, leads to syncope and falls, and is recognised as a frequent and clinically important problem, particularly in the elderly and patients with autonomic dysfunction, the latter often secondary to diabetes mellitus ${ }^{(1,2)}$. $\mathrm{PPH}$ is distinct from, and occurs more frequently than, orthostatic hypotension ${ }^{(1)}$. The mechanisms responsible for PPH are poorly defined; however, several factors including meal composition, gastric distension, small-intestinal nutrient delivery, splanchnic blood flow and neural and hormonal mechanisms appear important ${ }^{(1,3-7)}$. An understanding of these mechanisms is pivotal for the effective management of $\mathrm{PPH}$, which is currently suboptimal.
The onset of the fall in $\mathrm{BP}$ is usually evident soon after a meal, with a maximum response at $30-60 \mathrm{~min}^{(1)}$, suggesting a relationship to the delivery of nutrients to the small intestine, which has proven to be the case. When glucose is administered intraduodenally to healthy older subjects at rates of $4.2 \mathrm{~kJ} / \mathrm{min}(1 \mathrm{kcal} / \mathrm{min})$ or $12 \cdot 6 \mathrm{~kJ} / \mathrm{min}(3 \mathrm{kcal} / \mathrm{min})^{(7,8)}$, i.e. within the normal physiological range of gastric emptying $(\mathrm{GE})^{(9)}$, the fall in $\mathrm{BP}$ is much greater in response to $12.6 \mathrm{~kJ} /$ min $(3 \mathrm{kcal} / \mathrm{min})$ when compared with $4.2 \mathrm{~kJ} / \mathrm{min}(1 \mathrm{kcal} /$ min). In contrast, gastric distension, probably even at low volumes, attenuates the fall in $\mathrm{BP}^{(5,6,10)}$. Ingestion of carbohydrate, particularly glucose, was believed to have the greatest suppressive effect on $\mathrm{BP}^{(11)}$ when compared with fat and

Abbreviations: AUC, area under the curve; BP, blood pressure; bpm, beats per min; G, glucose; GE, gastric emptying; GIP, glucose-dependent insulinotropic polypeptide; GLP-1, glucagon-like peptide-1; POM, three-dimensional positioning and orientation measurement; PPH, postprandial hypotension; $\mathrm{X}, \mathrm{D}$-xylose; W, water. 
protein $^{(11)}$, but recent studies by our group have shown that oral $^{(12)}$ and intraduodenal ${ }^{(12,13)}$ infusion of fat, protein and glucose $^{(13)}$ induces comparable falls in BP in healthy older subjects, although the hypotensive response to glucose occurs earlier than with fat or protein ${ }^{(12,13)}$. There is little information about the effect of different carbohydrates on postprandial BP, particularly those that are absorbed more slowly than glucose. Xylose is a poorly absorbed pentose, commonly found in plant cell walls, which is used as a food additive to produce a 'savoury' flavour ${ }^{(14)}$. Information relating to the effects of xylose on BP is inconsistent. It has been reported that there is no fall in BP after oral xylose in amounts of $42^{(15)}$ and $0.83 \mathrm{~g} / \mathrm{kg}$ body weight ${ }^{(16)}$ in healthy older subjects who exhibited a fall in $\mathrm{BP}$ following oral glucose, whereas Mathias et al. ${ }^{(17,18)}$ suggested that there is a small fall in BP following oral xylose. A limitation of these studies $^{(15-18)}$ was that GE of glucose and xylose was not measured, and differences in the rate of carbohydrate delivery into the small intestine may have, accordingly, influenced the observations. In monkeys, the GE of xylose apparently occurs in a similar fashion to that of glucose; i.e. in an overall linear pattern and more slowly with increasing concentration, presumably as a result of inhibitory feedback arising from the small intestine ${ }^{(19)}$. In contrast, in humans, xylose $(25 \mathrm{~g})$ has been reported to markedly prolong GE when compared with the same amount of glucose ${ }^{(20)}$.

The 'incretin hormones', glucose-dependent insulinotropic polypeptide (GIP) and glucagon-like peptide-1 (GLP-1), are responsible for the substantially greater insulin response to oral glucose compared with isoglycaemic intravenous glucose loads ${ }^{(21)}$. GLP-1 is secreted by L-cells located predominately in the distal small intestine and colon, and suppresses glucagon secretion, as well as stimulating glucose-dependent insulin secretion, while GIP is released from the K-cells, which are located predominantly in the proximal small intestine ${ }^{(21,22)}$. Recent observations have suggested that GLP-1 may have a protective role in PPH. In humans ${ }^{(23)}$ and animals ${ }^{(24)}$, exogenous administration of GLP-1 may increase BP. We have reported that the $\alpha$-glucosidase inhibitor, acarbose, which is used frequently in the management of type 2 diabetes, attenuates the fall in BP induced by oral sucrose in healthy older subjects, slows GE and markedly stimulates the secretion of GLP- ${ }^{(25)}$. The latter effect presumably reflects the presence of carbohydrate in the small intestine. In dogs, there was no increase in the release of GLP-1 following an infusion of xylose into an ileal loop ${ }^{(26)}$. The effects of carbohydrate on GLP-1 secretion may, however, be species-dependent ${ }^{(27)}$, and there is no information about the effects of xylose on GIP and GLP-1 in humans.

The aims of the present study were to determine the effects of oral xylose on BP, GE and incretin hormone secretion, when compared with oral glucose and water, in healthy older subjects.

\section{Materials and methods}

\section{Subjects}

A total of eight healthy older subjects (six males and two females), with a median age of 70.5 (range 65-75) years and BMI of 23.5 (range $20 \cdot 4-27 \cdot 1$ ) $\mathrm{kg} / \mathrm{m}^{2}$, were recruited by advertisement. All were non-smokers, and none had a history of gastrointestinal disease or surgery, diabetes, significant respiratory, renal, hepatic or cardiac disease, intake of $>20 \mathrm{~g}$ alcohol/d or was taking medication known to influence BP or gastrointestinal function.

\section{Protocol}

The protocol was approved by the Human Research Ethics Committee of the Royal Adelaide Hospital, and each subject provided written informed consent. All experiments were carried out in accordance with the Declaration of Helsinki.

Each subject was studied on three occasions in a randomised, double-blind order; each study day was separated by a minimum of $3 \mathrm{~d}$. On each day, the subject attended the laboratory at 08.00 hours following an overnight fast ( $10 \mathrm{~h}$ for solids and $8 \mathrm{~h}$ for liquids). An intravenous cannula was placed in a left antecubital vein for blood sampling, and an automated BP cuff positioned around the right arm for the measurement of BP and heart rate. Each subject was then allowed to rest, seated in a chair, for about $30 \mathrm{~min}$. At $t=-2 \mathrm{~min}$, the subject consumed a $300 \mathrm{ml}$ drink comprising either (1) water $(50 \mathrm{ml}$ low-energy lemon cordial (Bickford's, Adelaide, SA, Australia) + $250 \mathrm{ml}$ water) - 'W', (2) $50 \mathrm{~g}$ glucose monohydrate (dissolved in $50 \mathrm{ml}$ low-energy lemon cordial $+155 \mathrm{ml}$ water $+80 \mathrm{ml}$ hypertonic saline (3\%)) - ' $\mathrm{G}$ ' or (3) $50 \mathrm{~g}$ $\mathrm{D}$-xylose (dissolved in $50 \mathrm{ml}$ low-energy lemon cordial +235 ml water) - ' $\mathrm{X}$ ', within $2 \mathrm{~min}$. Both carbohydrate drinks were isoenergetic (approximately $782.4 \mathrm{~kJ}(187 \mathrm{kcal})$ ) and iso-osmolar (approximately $1350 \mathrm{mOsmol}$ ). GE, BP (systolic and diastolic) and heart rate were then measured for $120 \mathrm{~min}$. On one day, cardiovascular autonomic nerve function was evaluated immediately after the completion of the study ${ }^{(28,29)}$.

\section{Measurements}

Blood pressure and heart rate. BP (systolic and diastolic) and heart rate were measured using an automated oscillometric BP monitor (DINAMAP ProCare 100; GE Medical Systems, Milwaukee, WI, USA) before the consumption of the drink and then every $3 \mathrm{~min}$ between $t=0$ and $120 \mathrm{~min}^{(7)}$. 'Baseline' BP and heart rate, i.e. ' $t=0 \mathrm{~min}$ ', were calculated as the mean of measurements taken at $t=-9,-6$ and $-3 \mathrm{~min}$. PPH was defined as a fall in systolic BP of $\geq 20 \mathrm{mmHg}$ that was sustained for at least $30 \mathrm{~min}$. ${ }^{(1)}$

Gastric emptying. GE was assessed using three-dimensional ultrasonography, using a Logiq $^{\text {TM }} 9$ ultrasonography system (GE Healthcare Technologies, Sydney, Australia) with TruScan Architecture (i.e. built-in magnetically sensored three-dimensional) ${ }^{(30)}$. For three-dimensional positioning and orientation measurement (POM), a transmitter was placed close to the subject, and a snap-on sensor attached to a $3.5 \mathrm{C}$ 
broad-spectrum $2 \cdot 5-4 \mathrm{MHz}$ convex transducer ${ }^{(30,31)}$. As the transmitter produces a spatially varying magnetic field, and ferrous and conductive metals distort the magnetic field, all metal objects were removed from the subject and from the area directly between the POM transmitter and sensor ${ }^{(32)}$. The POM transmitter was placed behind (approximately $10 \mathrm{~cm}$ ) the subject ${ }^{(33)}$, at the level of the stomach, so that the subject was positioned between the ultrasound scanner and the transmitter. For three-dimensional data acquisition, the subject was scanned at $t=-2$ and 0 min (i.e. immediately following drink consumption) and then at $15 \mathrm{~min}$ intervals between $t=0$ and $120 \mathrm{~min}$. A region of interest was drawn around the total stomach, and the volume of the drink in the total stomach was derived and expressed as a percentage of the original volume at $t=0 \mathrm{~min}$ (i.e. $100 \%)^{(30)}$. GE curves (expressed as \% retention over time) were derived for the total stomach at $t=0,15,30,45,60,75,90,105$ and $120 \mathrm{~min}$. The $50 \%$ GE time was also determined.

Blood glucose, serum insulin, glucagon-like peptide-1 and glucose-dependent insulinotropic polypeptide concentrations. Venous blood samples were obtained before consumption of the drink (i.e. $t=-2 \mathrm{~min}$ ) and at $15 \mathrm{~min}$ intervals between $t=0$ and $120 \mathrm{~min}$. Blood glucose concentrations ( $\mathrm{mmol} / \mathrm{l})$ were determined immediately using a portable blood glucose meter (Medisense Precision Q.I.D ${ }^{\mathrm{TM}}$ System; Abbott Laboratories, Medisense Products, Inc., Bedford, MA, USA).

Serum was separated by centrifugation at $3200 \mathrm{rpm}$ for $15 \mathrm{~min}$ at $4^{\circ} \mathrm{C}$ within $30 \mathrm{~min}$ of collection and stored at $-70^{\circ} \mathrm{C}$ until analysed. Serum insulin $(\mathrm{mU} / \mathrm{l})$ was measured by ELISA immunoassay (Diagnostics Systems Laboratories, Inc., Webster, TX, USA). Sensitivity of the assay was $0.26 \mathrm{mU} / 1$, and $\mathrm{CV}$ was $2.6 \%$ within assays and $6.2 \%$ between assays $^{(34)}$.

Serum GLP-1 (pmol/1) was measured by RIA (GLPIT-36HK; Linco Research, St Charles, MO, USA). Minimum detection limit was 3 pmol/1, intra-assay $\mathrm{CV}$ was $6.7 \%$ and inter-assay $\mathrm{CV}$ was $7 \cdot 8 \%$.

Serum GIP (pmol/l) was measured by RIA with some modifications to the original method ${ }^{(35)}$. The standard curve was prepared in buffer rather than in extracted charcoal-stripped serum, and the radio-iodinated label was supplied by Perkin Elmer (Boston, MA, USA). Minimum detection limit of the assay was $2 \mathrm{pmol} / \mathrm{l}$, and both intra- and inter-assay $\mathrm{CV}$ were $11 \cdot 2$ and $11.6 \%$, respectively.

Autonomic function. Autonomic nerve function was assessed using standardised cardiovascular reflex tests ${ }^{(28,29)}$. In brief, parasympathetic function was evaluated by the variation ( $\mathrm{R}-\mathrm{R}$ interval) of the heart rate during deep breathing and the response to standing ('30:15' ratio). Sympathetic function was assessed by the fall in systolic BP in response to standing. Each of the test results was scored according to age-adjusted predefined criteria as $0=$ normal, $1=$ borderline and $2=$ abnormal for a total maximum score of 6 . A score $>3$ was considered to indicate autonomic dysfunction ${ }^{(28,29)}$.

Statistical analysis. Systolic and diastolic BP and heart rate were expressed as changes from baseline. GE, blood glucose, serum insulin, and GLP-1 and GIP concentrations were analysed as absolute values. One-way ANOVA was used to analyse the effects of 'time' on GE, systolic and diastolic BP, heart rate, blood glucose, serum insulin, and GLP-1 and GIP concentrations. The maximum fall in systolic and diastolic $\mathrm{BP}$ and maximum rise in heart rate were defined as the greatest change from baseline in each subject at any given time point for each treatment. For blood glucose, serum insulin, and GLP-1 and GIP concentrations, the peak absolute value was analysed in each subject at any given time point for each treatment. Areas under the curve (AUC), between $t=0$ and $120 \mathrm{~min}$, were calculated using the trapezoidal rule and analysed by one-way ANOVA to evaluate a 'treatment' effect for GE, systolic and diastolic BP and heart rate and between $t=-2$ and $120 \mathrm{~min}$ for blood glucose, serum insulin, and GLP-1 and GIP concentrations. All analyses were performed using SPSS version 16.0.2 (SPSS, Inc., Chicago, IL, USA). Data are shown as changes from baseline and means with their standard errors, unless otherwise stated. The number of subjects studied was based on power calculations derived from our previous work; the sample size of eight subjects was calculated to have $80 \%$ power at the $P=0.05$ significance level to detect a difference in maximum fall in systolic BP between glucose and xylose of $7.3 \mathrm{mmHg}^{(36)}$. A $P$ value $<0.05$ was considered significant in all analyses.

\section{Results}

The studies were well tolerated, and there were no adverse events. No subject had definite autonomic neuropathy (mean score $0 \cdot 9$, range $0-2$ ), or had PPH.

\section{Blood pressure and heart rate}

There was no difference in baseline $(t=0 \mathrm{~min}) \mathrm{BP}$ or heart rate between the $3 \mathrm{~d}$ : systolic BP ('W' 118.4 (SEM 6.0) $\mathrm{mmHg}$ $v$. 'G' 120.4 (SEM 7.0) mmHg $v$. ' $\mathrm{X}$ ' 118.9 (SEM 5.6) mmHg; $P=0.44)$; diastolic BP ('W' $69 \cdot 8$ (sem 2.6) mmHg $v$. 'G' $71 \cdot 1$ (sem 2.7) mmHg $v$. 'X' $70 \cdot 3$ (SEm 3.0) mmHg; $P=0.40$ ); heart rate ('W' 57.9 (SEM $2 \cdot 2$ ) beats per min (bpm) $v$. 'G' 58.8 (SEM $3 \cdot 0) \mathrm{bpm} v$. 'X' $59 \cdot 1$ (SEM 2.6) bpm; $P=0.79$ ).

\section{Systolic blood pressure}

Between $t=0$ and $120 \mathrm{~min}$, there was a fall in systolic BP during ' $\mathrm{G}$ ' $(P=0.02)$ and no change during 'W' $(P=0.71)$ or 'X' $(P=0.63) \quad$ (Fig. 1(a)). There was a treatment effect $(P<0.001)$ for the AUC of the change in systolic BP between $t=0$ and $120 \mathrm{~min}$, so that systolic BP was less during ' $\mathrm{G}$ ' when compared with 'W' and ' $\mathrm{X}$ ' ( $P=0.003$ for both), without any difference between ' $W$ ' and ' $X$ ' $(P=0 \cdot 19)$. During ' $G$ ', the maximum fall in BP was $15 \cdot 1$ (SEM 2.8) mmHg occurring at 64 (SEM 9) $\mathrm{min}$. At $t=120 \mathrm{~min}$, systolic BP was not different from baseline after 'W' (120.6 (SEM 6.0) $\mathrm{mmHg} ; P=0 \cdot 23$ ), 'G' (119.4 (sem 5.7) mmHg; $P=0.69$ ) or ' $\mathrm{X}$ ' (117.6.4 (sem 4.6) mmHg; $P=0 \cdot 43)$. 


\section{Diastolic blood pressure}

Between $t=0$ and $120 \mathrm{~min}$, there was a fall in diastolic BP during ' $G$ ' $(P=0.003)$, and no change during ' $\mathrm{W}$ ' $(P=0.88)$ or ' $\mathrm{X}$ ' $(P=0 \cdot 26) \quad$ (Fig. 1(b)). There was a treatment effect $(P<0.001)$ for the AUC of the change in diastolic BP between $t=0$ and $120 \mathrm{~min}$, so that diastolic BP was less during ' $\mathrm{G}$ ' when compared with 'W' $(P=0.002)$ and ' $\mathrm{X}$ ' $(P=0.005)$, without any significant difference between ' $\mathrm{W}$ ' and ' $\mathrm{X}$ ' $(P=0.92)$. During ' $G$ ', the maximum fall in BP was 12.9 (sem 1.6) $\mathrm{mmHg}$ occurring at 56 (SEM 11) $\mathrm{min}$. At $t=120 \mathrm{~min}$, diastolic BP was not different from baseline after ' $\mathrm{W}$ ' (70.3 (SEM 2.4) $\mathrm{mmHg}$;
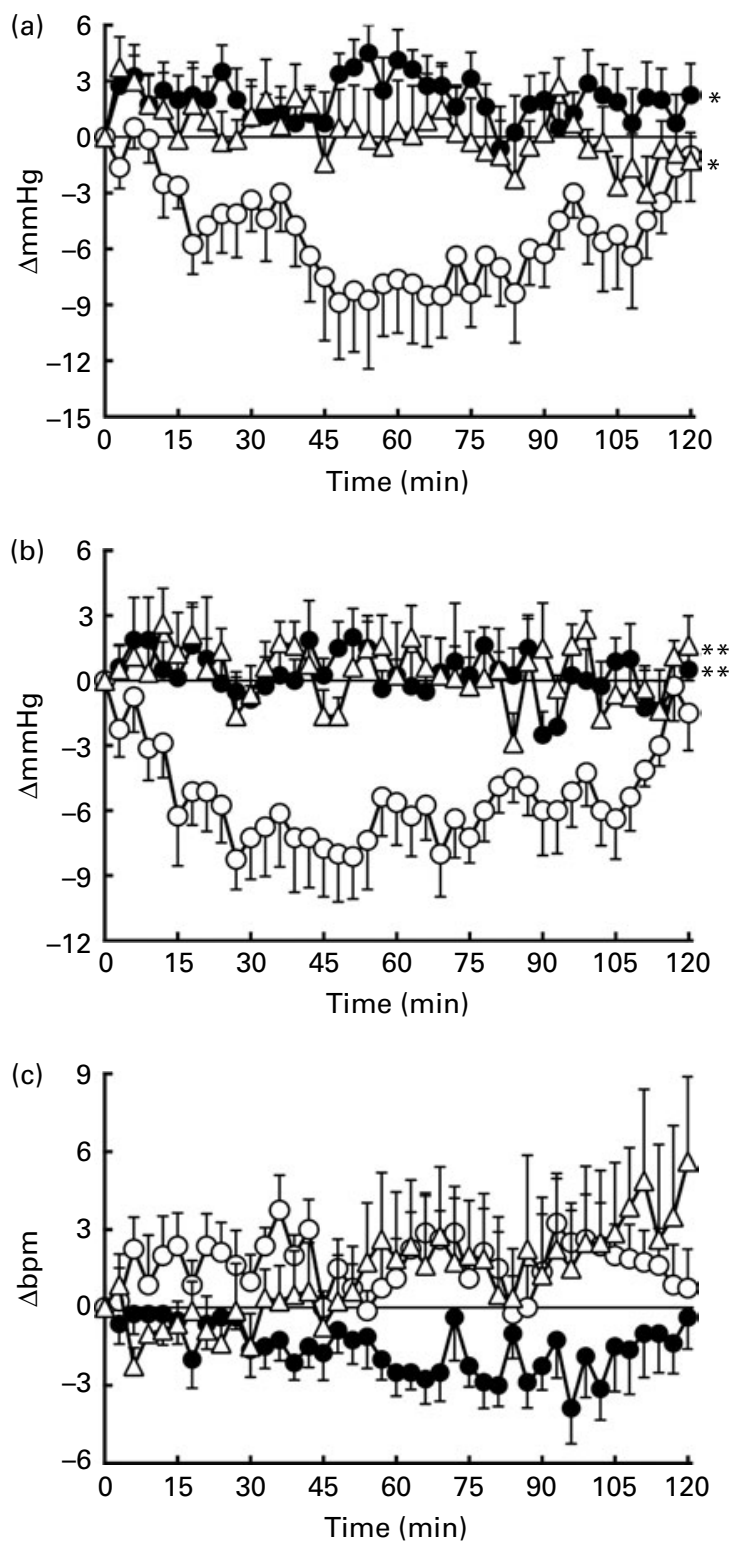

Fig. 1. Change in (a) systolic blood pressure, (b) diastolic blood pressure and (c) heart rate (in beats per min; bpm) from baseline in response to oral water $(\mathrm{W}, \bullet)$, glucose $(\mathrm{G}, \mathrm{O})$ and xylose $(\mathrm{X}, \Delta)$. Values are means, with their standard errors represented by vertical bars $(n 8)$. Mean values were significantly different for ' $G$ ' when compared with ' $W$ ' and ' $X$ ' for the systolic ( $\left.{ }^{\star} P=0.003\right)$ and diastolic ( $\left.{ }^{\star \star} P \leq 0.005\right)$ blood pressure treatment effects.
$P=0.58)$, 'G' $(69.6(\operatorname{sem} 3.3) \mathrm{mmHg} ; P=0.41)$ or ' $\mathrm{X}$ ' $(71.9$ (SEM 2.6) $\mathrm{mmHg} ; P=0 \cdot 27$ ).

\section{Heart rate}

Between $t=0$ and $120 \mathrm{~min}$, there was no significant change in heart rate during ' $\mathrm{W}$ ' $(P=0.22)$, ' $\mathrm{G}$ ' $(P=0.28)$ or ' $\mathrm{X}$ ' $(P=0 \cdot 19)$ (Fig. 1(c)). At $t=120 \mathrm{~min}$, heart rate was not significantly different from baseline after 'W' 57.5 (SEM 2.5) bpm; $P=0.77$ ), 'G' (59.5 (sem 2.8) bpm; $P=0.63)$ or ' $\mathrm{X}$ ' (64.8 (sem 5.1) bpm; $P=0 \cdot 13)$.

\section{Gastric emptying}

There was a significant treatment effect $(P<0 \cdot 001)$ for the AUC for GE between $t=0$ and $120 \mathrm{~min}$ (Fig. 2). 'W' emptied in an overall exponential, and more rapid, fashion when compared with ' $G$ ' and ' $\mathrm{X}$ ', which emptied linearly and more slowly ( $P<0.001$ for both), with no significant difference between ' $\mathrm{G}$ ' and ' $\mathrm{X}$ ' $(P=0 \cdot 47)$. The $50 \% \mathrm{GE}$ time of ' $\mathrm{W}$ ' $(t=19$ (sEm $3)$ min) was less than ' $G$ ' $(t=75(\operatorname{sem} 7) \min )$ and ' $X$ ' $(t=75$ (SEM 8) $\mathrm{min})(P<0 \cdot 001)$.

\section{Blood glucose}

There was no difference in baseline $(t=-2 \mathrm{~min})$ blood glucose between the $3 \mathrm{~d}$ ('W' $v$. 'G' $v$. 'X'): $6 \cdot 2(\operatorname{sem} 0 \cdot 2) \mathrm{mmol} / \mathrm{l}$ v. $6.2(\operatorname{sem} 0 \cdot 2) \mathrm{mmol} / 1 \quad v .6 \cdot 1 \quad(\operatorname{sem} \quad 0.2) \mathrm{mmol} / 1 ; \quad P=0.89$. Between $t=-2$ and $120 \mathrm{~min}$, there was a rise in blood glucose during ' $G$ ' $(P<0 \cdot 001)$, and a slight rise following ' $\mathrm{X}$ ' $(P=0.03)$, but no change during 'W' $(P=0.50)$ (Fig. 3(a)) There was a significant treatment effect $(P<0 \cdot 001)$ for the AUC of the blood glucose concentration between $t=-2$ and $120 \mathrm{~min}$, so that the magnitude of the rise in blood glucose was much greater during ' $G$ ' compared with both ' $W$ ' $(P \leq 0 \cdot 001)$ and 'X' $(P \leq 0 \cdot 001)$. During ' $G$ ', peak blood glucose was $10 \cdot 2(\operatorname{sem~} 0 \cdot 6) \mathrm{mmol} / \mathrm{l}$ at $53(\mathrm{sem} 8) \mathrm{min}$. At $t=120 \mathrm{~min}$, blood glucose concentrations were not different from baseline after 'W' (6.1 (sEm 0.1) mmol/1; $P=0.58), \quad$ G' $\quad(6.8 \quad$ (sEm

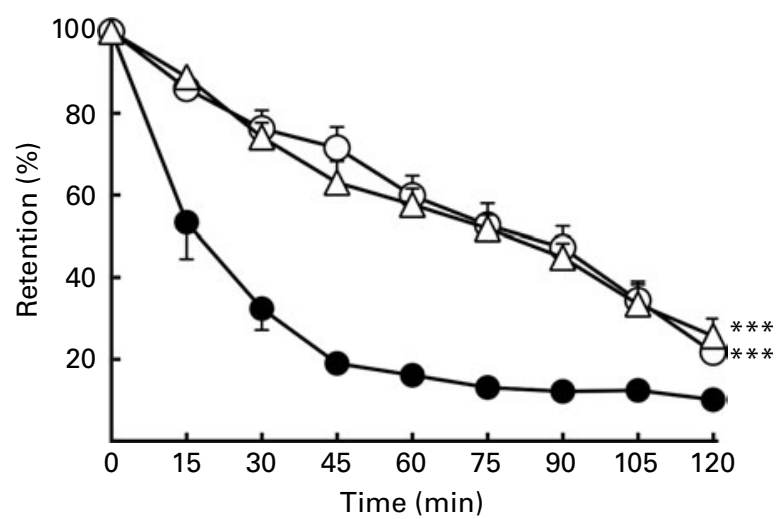

Fig. 2. Gastric emptying of water (W, $\bullet$ ), glucose $(\mathrm{G}, \mathrm{O})$ and xylose $(X, \triangle)$. Values are means, with their standard errors represented by vertical bars $(n$ 8). Mean values were significantly different for ' $W$ ' when compared with ' $G$ ' and ' $X$ ' in the treatment effect of the AUC ( $\left.{ }^{\star \star \star} P<0.001\right)$. 
$0.5) \mathrm{mmol} / \mathrm{l} ; P=0.33)$, but were slightly higher after ' $\mathrm{X}$ ' $(6.5$ (SEM $0 \cdot 2) \mathrm{mmol} / \mathrm{l} ; P=0 \cdot 03$ ).

\section{Serum insulin}

There was no difference in baseline $(t=-2 \mathrm{~min})$ serum insulin between the $3 \mathrm{~d}$ ('W' $v$. 'G' $v$. 'X'): 8.7 (SEm 1.3) v. 8.5 (sem 1.1) v. 8.4 (SEm 1.6) $\mathrm{mU} / \mathrm{l} ; \quad P=0.88$. Between $t=-2$ and $120 \mathrm{~min}$, there was a rise in serum insulin during ' $\mathrm{G}$ ' $(P<0.001)$, a trend for a fall during ' $\mathrm{W}$ ' $(P=0.06)$ and no change during ' $\mathrm{X}$ ' $(P=0 \cdot 18)$ (Fig. 3(b)). There was a significant treatment effect $(P<0.001)$ for the AUC of serum insulin between $t=-2$ and $120 \mathrm{~min}$, so that the magnitude of the rise in serum insulin was much greater during ' $G$ ' compared with 'W' and ' $\mathrm{X}$ ' $(P<0.001$ for both), without any significant difference between ' $\mathrm{W}$ ' compared with ' $\mathrm{X}$ ' $(P=0 \cdot 13)$. At $t=120 \mathrm{~min}$, serum insulin concentrations were not different from baseline after ' $\mathrm{X}$ ' (8.0 (SEM 1.6) mU/1; $P=0.63)$, slightly lower following 'W' (7.3 (SEM 1.0) mU/1; $P=0.03)$ and substantially higher after ' $G$ ' (42.8 (sem 10.1) mU/1; $P=0.009)$.

\section{Serum glucagon-like peptide-1}

There was no significant difference in baseline $(t=-2 \mathrm{~min})$ serum GLP-1 between the $3 \mathrm{~d}$ ('W' $v$. 'G' $v$. ' $\mathrm{X}$ '): $16 \cdot 6$ (sEm 2.3) v. $13 \cdot 8(\operatorname{sem~1.4)~v.~} 18.9(\operatorname{sem} 3 \cdot 3) \mathrm{pmol} / \mathrm{l} ; P=0 \cdot 08$. Between $t=-2$ and $120 \mathrm{~min}$, there was a rise in serum GLP-1 during ' $\mathrm{G}$ ' $(P=0.01)$ and ' $\mathrm{X}$ ' $(P<0.001)$, but no change during ' $\mathrm{W}$ ' $(P=0.39)$ (Fig. 3(c)). There was a significant treatment effect $(P \leq 0 \cdot 001)$ for the AUC of serum GLP-1 concentration between $t=-2$ and $120 \mathrm{~min}$, so that the magnitude of the rise in serum GLP-1 was much greater during ' $\mathrm{X}$ ' compared with ' $\mathrm{W}$ ' $(P \leq 0.001)$ and ' $G$ ' $(P=0.002)$, with a trend for a difference between ' $G$ ' compared with 'W' $(P=0 \cdot 07)$. During ' $G$ ', peak GLP-1 was 30.5 (SEM 4.6 ) pmol/1 at 26 (sem 5) min, and during ' $\mathrm{X}$ ', peak GLP-1 was 42.0 (SEM 4.0 ) pmol/1 at 48 (SEM 5) min $(P<0.05$ for peak and $P<0.01$ for time to peak). At $t=120 \mathrm{~min}$, serum GLP-1 concentrations were not different from baseline after 'W' $(15.7$ (SEM 1.2) pmol/1; $P=0 \cdot 15)$ and 'G' (12.3 (sEm 1.0) pmol/1; $P<0 \cdot 001)$, but higher following 'X' (27.2 (sem 1.8) pmol/1; $P=0 \cdot 002)$.

\section{Serum glucose-dependent insulinotropic polypeptide}

There was no significant difference in baseline $(t=-2 \mathrm{~min})$ serum GIP between the $3 \mathrm{~d}$ ('W' $v$. 'G' $v$. 'X'): $17 \cdot 3$ (SEm 1.3) v. 18.4 (SEM 1.6) pmol/1 v. 18.9 (SEM 1.6) $\mathrm{pmol} / \mathrm{l} ; \quad P=0.30$. Between $t=-2$ and $120 \mathrm{~min}$, there was a prompt rise in serum GIP during 'G' $(P<0 \cdot 001)$, and a fall, albeit minor, during 'W' and ' $\mathrm{X}$ ' $(P<0.001$ for both) (Fig. 3(d)). There was a significant treatment effect $(P \leq 0.001)$ of the AUC for serum GIP concentration between $t=-2$ and $120 \mathrm{~min}$, so that the magnitude of the rise in serum GIP was much greater during ' $G$ ' compared with ' $W$ ' and ' $X$ ' ( $P \leq 0.001$ for both), without any difference between ' $\mathrm{W}$ ' compared with ' $\mathrm{X}$ ' $(P=0.41)$. During ' $G$ ', peak GIP was 61.0 (SEM 8.0) pmol/1 at 56 (SEM 11) min. At $t=120 \mathrm{~min}$, serum GIP concentrations were not different from baseline after 'W' (15.7 (SEM 2.0) pmol/l; $P=0 \cdot 15)$, less following ' $\mathrm{X}$ ' (16.2 (sem 1.1) pmol/1; $P=0.02)$ and greater after ' $G$ ' (48.9 (sem 4.7) pmol/1; $P<0.001)$.

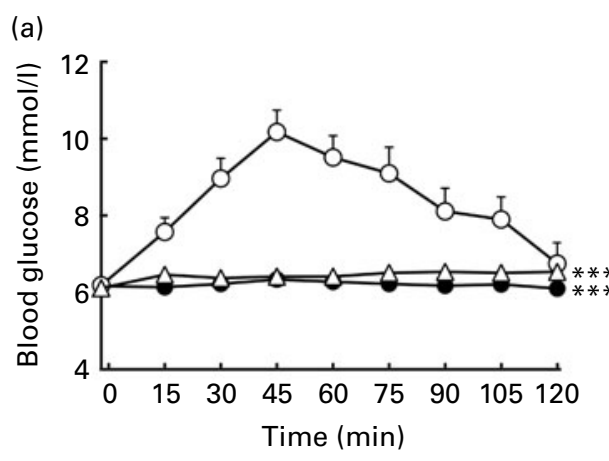

(b)
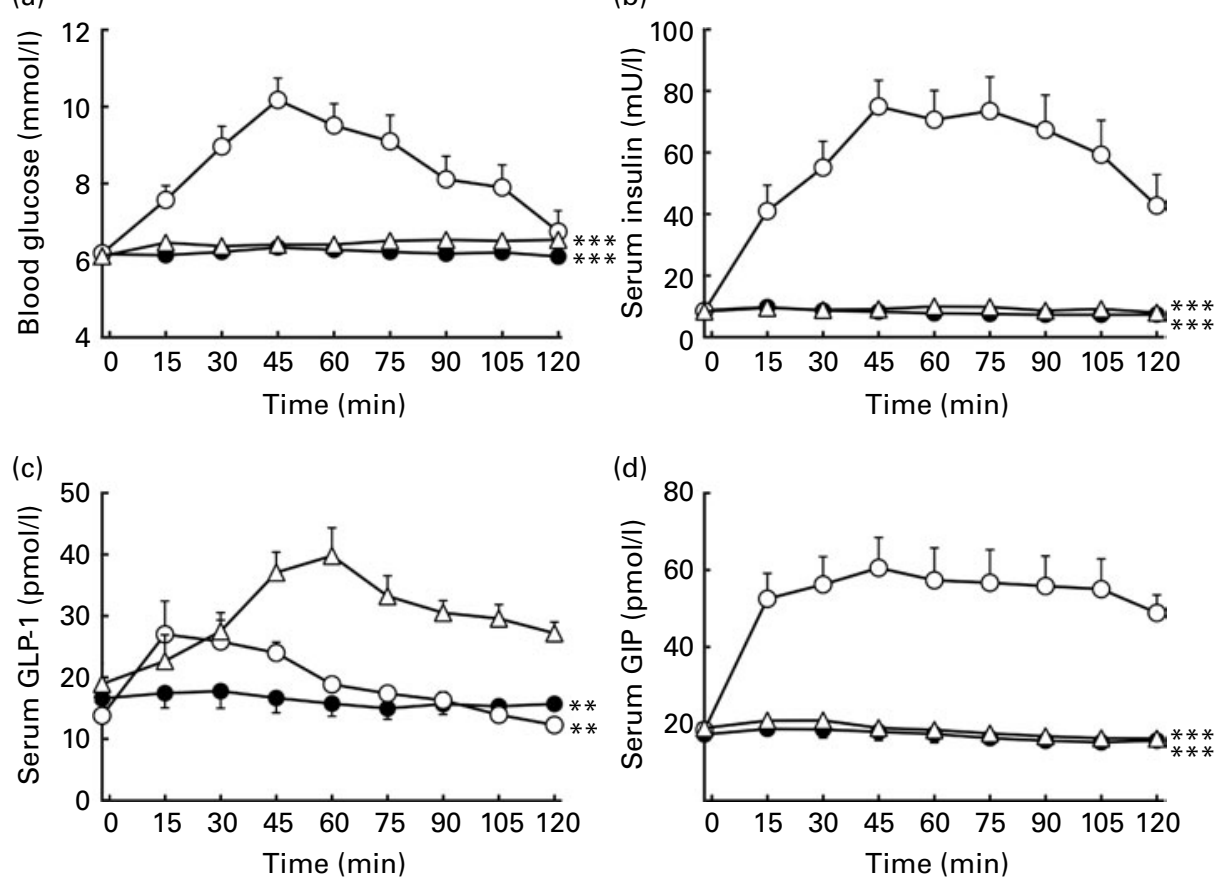

Fig. 3. Change in (a) blood glucose, (b) serum insulin, (c) serum glucagon-like peptide-1 (GLP-1) and (d) serum glucose-dependent insulinotropic polypeptide $(\mathrm{GIP})$ in response to oral water $(\mathrm{W}, \bullet)$, glucose $(\mathrm{G}, O)$ and xylose $(\mathrm{X}, \triangle)$. Values are means, with their standard errors represented by vertical bars $(n 8)$. Mean values were significantly different for ' $G$ ' when compared with 'W' and ' $X$ ' for the blood glucose, serum insulin and serum GIP effects ( ${ }^{\star \star \star} P \leq 0.001$ ). Mean values were significantly different for ' $X$ ' when compared with ' $W$ ' and ' $G$ ' for the serum GLP-1 treatment effect $\left({ }^{\star \star} P \leq 0 \cdot 01\right)$. 


\section{Discussion}

The present study indicates that oral xylose (50 g), unlike glucose, has no effect on BP in healthy older subjects despite emptying from the stomach at a comparable rate. Xylose is also more potent than glucose in stimulating GLP-1, but has no effect on GIP and has minimal effect on glycaemia and insulinaemia, at least during euglycaemia.

The present study confirms that oral glucose induces a substantial fall $(15 \cdot 1$ (SEM $2 \cdot 8) \mathrm{mmHg}$ ) in systolic BP in healthy older subjects, studied under resting conditions. Previous studies relating to the effects of xylose on BP have been inconsistent $^{(15-18)}$, but GE was not measured in any of these studies, and may have potentially accounted for the observations, given that the rate of nutrient delivery into the small intestine affects the fall in BP both as a result of gastric distension $^{(10,37)}$ and as a result of the exposure of the small intestine to nutrients ${ }^{(7)}$.

The present study establishes that glucose and xylose empty from the stomach at a comparable rate with an overall linear pattern that is substantially slower than water, which empties exponentially, consistent with a previous animal (primate) study $^{(19)}$. Hence, GE does not account for the different effects of glucose and xylose on BP. The regulation of the GE of nutrients arises predominantly as a result of inhibitory feedback from receptors in the small intestine, the magnitude of which is dependent on the length and, possibly, region ${ }^{(38)}$ of the small intestine exposed, as influenced by the energy load. Accordingly, it appears that the magnitude of this inhibitory feedback is comparable for xylose and glucose, although the mechanism(s) which account for this feedback may differ ${ }^{(19)}$. In humans, a study in healthy adult males reported that xylose in a dose of $25 \mathrm{~g}$ in $50 \mathrm{ml}$ water, given immediately after the consumption of a scrambled egg meal, markedly prolonged GE, when compared with the same amount of glu$\operatorname{cose}^{(20)}$. Differences in the rate of the GE of xylose between these studies, possibly influenced by the xylose dose, may account for the discrepant observations.

While it is clear that differences in GE do not account for the substantial, differential effects of xylose and glucose on BP, the two sugars had discrepant effects on glycaemia, insulinaemia and the secretion of the incretin hormones, GIP and GLP-1, which, accordingly, warrant consideration. It is well documented, and confirmed in the present study, that xylose has minimal, if any, effect on plasma glucose or insulin ${ }^{(16-18)}$. However, both hyperglycaemia and hyperinsulinaemia are unlikely to play a major role in $\mathrm{PPH}$, e.g. intravenous glucose has little, if any, effect on $\mathrm{BP}^{(39)}$. The comparative effects of xylose and glucose on splanchnic blood flow remain to be determined, and it is possible that the relatively poorly absorbed xylose induces a lesser increase. This is the first evaluation of the effect of xylose on the release of GLP-1 and GIP - that xylose had no effect on GIP is predictable, given that the secretion of GIP occurs predominantly in the proximal small intestine and, in the case of carbohydrate, appears to be dependent on an affinity for the transporter, sodium-dependent glucose cotransporter- $1^{(27)}$. There is also no evidence that GIP affects BP. It has been reported that xylose has no effect on GLP-1 secretion in the $\operatorname{dog}^{(26)}$, although xylose apparently stimulates the release of glucagon-like immunoreactivity in the canine intestine ${ }^{(40)}$. The present study establishes that xylose is a potent stimulant of GLP-1 in humans - the sustained stimulation is likely to reflect the delay in intestinal absorption when compared with glucose, so that the distal small intestine is exposed; the initial stimulation appeared similar to that induced by glucose. It is not surprising that the stimulation of GLP-1 by xylose was not associated with a substantial increase in serum insulin in the present study, as the insulinotropic property of GLP-1 is known to be glucose-dependent, i.e. GLP-1 has little, if any, effect on insulin during euglycaemia ${ }^{(21)}$ It is accordingly probable that xylose will stimulate insulin in type 2 patients during hyperglycaemia by increasing GLP-1. The stimulation of GLP-1 secretion by xylose may also be of relevance to the use of dipeptidyl peptidase-IV inhibitors and GLP-1 analogues in the management of type 2 diabetes $^{(41)}$. As discussed, this stimulation of GLP-1 may account for the absence of any fall in BP. We studied a small number of subjects precluding assessment of meaningful correlations. Further studies are required to address this issue, including the effects of different xylose loads. Given that GLP-1 plays a physiological role to slow $\mathrm{GE}^{(42)}$, it is perhaps surprising that xylose did not empty from the stomach slower than glucose. However, it should also be recognised that glucose ingestion increased the blood glucose concentration substantially, whereas xylose did not, and elevations of blood glucose, even within a normal postprandial range, slow $\mathrm{GE}^{(43)}$. It is also not known whether the presence of xylose in a glucose drink could attenuate the fall in BP. Furthermore, the effects of xylose in patients with $\mathrm{PPH}$ remain to be determined. In considering the potential dietary use of xylose, it should be recognised that while xylose is palatable, it is relatively expensive. In view of our observations, it would be of interest to evaluate the effects of the related pentose sugar, xylitol ${ }^{(44)}$, which is considerably cheaper.

In summary, in healthy older subjects, oral xylose, unlike glucose in a dose of $50 \mathrm{~g}$, has no effect on BP, despite emptying from the stomach at a comparable rate with glucose, and is a potent stimulant of GLP-1 secretion. These observations suggest that xylose may represent an alternative sweetener to glucose in the management of $\mathrm{PPH}$.

\section{Acknowledgements}

The authors have no conflicts of interest or financial interests to declare. The present study was supported by the National Health and Medical Research Council (NHMRC) of Australia. Professor Jones' and Professor Feinle-Bisset's salaries are funded by the NHMRC of Australia, and Dr Gentilcore was supported by a Postdoctoral Fellowship from the National Heart Foundation of Australia (PR 07A 3309). The purchase of the Logiq ${ }^{\mathrm{TM}} 9$ ultrasonography system was supported by an Equipment Grant from the NHMRC of Australia and funds from the University of Adelaide and GE Medical Systems Australia. The authors' contributions are as follows: L. V. performed the acquisition of subjects, data collection, analysis 
and interpretation, and preparation of the manuscript; T. H. and D. G. contributed to the data collection and preparation of the manuscript; R. S. R. performed the data collection; C. K. R. and C. F.-B. contributed to the preparation of the manuscript; M. H. performed the data analysis and interpretation, and contributed to the preparation of the manuscript; K. L. J. contributed to the concept and design of the study, data analysis and interpretation, and preparation of the manuscript.

\section{References}

1. Jansen RW \& Lipsitz LA (1995) Postprandial hypotension: epidemiology, pathophysiology, and clinical management. Ann Intern Med 122, 286-295.

2. Mathias CJ (1991) Postprandial hypotension. Pathophysiological mechanisms and clinical implications in different disorders. Hypertension 18, 694-704.

3. Sidery MB, Cowley AJ \& MacDonald IA (1993) Cardiovascular responses to a high-fat and a high-carbohydrate meal in healthy elderly subjects. Clin Sci (Lond) 84, 263-270.

4. Jordan J, Shannon JR, Black BK, et al. (2000) The pressor response to water drinking in humans: a sympathetic reflex? Circulation 101, 504-509.

5. Rossi P, Andriesse GI, Oey PL, et al. (1998) Stomach distension increases efferent muscle sympathetic nerve activity and blood pressure in healthy humans. J Neurol Sci 161, 148-155.

6. Shannon JR, Diedrich A, Biaggioni I, et al. (2002) Water drinking as a treatment for orthostatic syndromes. Am J Med 112, 355-360.

7. O'Donovan D, Feinle C, Tonkin A, et al. (2002) Postprandial hypotension in response to duodenal glucose delivery in healthy older subjects. J Physiol 540, Pt 2, 673-679.

8. Vanis L, Gentilcore D, Rayner CK, et al. (2009) Effects of glucose load on blood pressure, heart rate and splanchnic blood flow in healthy elderly. J Nutr Health Aging $\mathbf{1 3}$ Suppl. 1, S478.

9. Brener W, Hendrix TR \& McHugh PR (1983) Regulation of the gastric emptying of glucose. Gastroenterology $\mathbf{8 5}, 76-82$.

10. Gentilcore D, Meyer JH, Rayner CK, et al. (2008) Gastric distension attenuates the hypotensive effect of intraduodenal glucose in healthy older subjects. Am J Physiol Regul Integr Comp Physiol 295, R472-R477.

11. Jansen RW, Peeters TL, Van Lier HJ, et al. (1990) The effect of oral glucose, protein, fat and water loading on blood pressure and the gastrointestinal peptides VIP and somatostatin in hypertensive elderly subjects. Eur J Clin Invest 20, 192-198.

12. Visvanathan R, Horowitz M \& Chapman I (2006) The hypotensive response to oral fat is comparable but slower compared with carbohydrate in healthy elderly subjects. $\mathrm{Br}$ J Nutr 95, 340-345.

13. Gentilcore D, Hausken T, Meyer JH, et al. (2008) Effects of intraduodenal glucose, fat, and protein on blood pressure, heart rate, and splanchnic blood flow in healthy older subjects. Am J Clin Nutr 87, 156-161.

14. Arnoldi A, Corain EA, Scaglioni L, et al. (1997) New coloured compounds from the Maillard reaction between xylose and lysine. J Agric Food Chem 45, 650-655.

15. Robinson BJ, Stowell LI, Purdie GL, et al. (1992) Autonomic responses to carbohydrate ingestion and head-up tilt in elderly subjects with orthostatic hypotension. Clin Auton Res 2, 309-316.
16. Robinson TG \& Potter JF (1995) Postprandial and orthostatic cardiovascular changes after acute stroke. Stroke 26, 1811-1816.

17. Mathias CJ, da Costa DF, McIntosh CM, et al. (1989) Differential blood pressure and hormonal effects after glucose and xylose ingestion in chronic autonomic failure. Clin Sci (Lond) 77, 85-92.

18. Mathias CJ (1990) Effect of food intake on cardiovascular control in patients with impaired autonomic function. J Neurosci Methods 34, 193-200.

19. Moran TH \& McHugh PR (1981) Distinctions among three sugars in their effects on gastric emptying and satiety. $\mathrm{Am}$ J Physiol 241, R25-R30.

20. Shafer RB, Levine AS, Marlette JM, et al. (1985) Do calories, osmolality, or calcium determine gastric emptying? $\mathrm{Am}$ J Physiol 248, Pt 2, R479-R483.

21. Holst JJ \& Gromada J (2004) Role of incretin hormones in the regulation of insulin secretion in diabetic and nondiabetic humans. Am J Physiol Endocrinol Metab 287, E199-E206.

22. Schirra J, Nicolaus M, Roggel R, et al. (2006) Endogenous glucagon-like peptide 1 controls endocrine pancreatic secretion and antro-pyloro-duodenal motility in humans. Gut 55, 243-251.

23. Edwards CM, Todd JF, Ghatei MA, et al. (1998) Subcutaneous glucagon-like peptide-1 (7-36) amide is insulinotropic and can cause hypoglycaemia in fasted healthy subjects. Clin Sci (Lond) 95, 719-724.

24. Barragan JM, Rodriguez RE, Eng J, et al. (1996) Interactions of exendin-(9-39) with the effects of glucagon-like peptide-1-(7-36) amide and of exendin- 4 on arterial blood pressure and heart rate in rats. Regul Pept 67, 63-68.

25. Gentilcore D, Bryant B, Wishart JM, et al. (2005) Acarbose attenuates the hypotensive response to sucrose and slows gastric emptying in the elderly. Am J Med 118, 1289.

26. Shima K, Suda T, Nishimoto K, et al. (1990) Relationship between molecular structures of sugars and their ability to stimulate the release of glucagon-like peptide-1 from canine ileal loops. Acta Endocrinol (Copenh) 123, 464-470.

27. Baggio LL \& Drucker DJ (2007) Biology of incretins: GLP-1 and GIP. Gastroenterology 132, 2131-2157.

28. Ewing DJ \& Clarke BF (1982) Diagnosis and management of diabetic autonomic neuropathy. Br Med J (Clin Res Ed) $\mathbf{2 8 5}$, 916-918.

29. Piha SJ (1991) Cardiovascular autonomic reflex tests: normal responses and age-related reference values. Clin Physiol 11, $277-290$.

30. Gentilcore D, Hausken T, Horowitz M, et al. (2006) Measurements of gastric emptying of low- and high-nutrient liquids using 3D ultrasonography and scintigraphy in healthy subjects. Neurogastroenterol Motil 18, 1062-1068.

31. Tefera S, Gilja OH, Olafsdottir E, et al. (2002) Intragastric maldistribution of a liquid meal in patients with reflux oesophagitis assessed by three dimensional ultrasonography. Gut 50, 153-158.

32. Liao D, Gregersen H, Hausken T, et al. (2004) Analysis of surface geometry of the human stomach using real-time 3-D ultrasonography in vivo. Neurogastroenterol Motil 16, 315-324.

33. Gilja OH, Detmer PR, Jong JM, et al. (1997) Intragastric distribution and gastric emptying assessed by three-dimensional ultrasonography. Gastroenterology 113, 38-49.

34. O'Donovan DG, Doran S, Feinle-Bisset C, et al. (2004) Effect of variations in small intestinal glucose delivery on plasma glucose, insulin, and incretin hormones in healthy subjects and type 2 diabetes. J Clin Endocrinol Metab 89, 3431-3435. 
35. Wishart J, Morris HA \& Horowitz M (1992) Radioimmunoassay of gastric inhibitory polypeptide in plasma. Clin Chem 38, 2156-2157.

36. Visvanathan R, Chen R, Garcia M, et al. (2005) The effects of drinks made from simple sugars on blood pressure in healthy older people. Br J Nutr 93, 575-579.

37. Jones KL, Tonkin A, Horowitz M, et al. (1998) Rate of gastric emptying is a determinant of postprandial hypotension in non-insulin-dependent diabetes mellitus. Clin Sci (Lond) 94, 65-70.

38. Lin HC, Doty JE, Reedy TJ, et al. (1989) Inhibition of gastric emptying by glucose depends on length of intestine exposed to nutrient. Am J Physiol 256, Pt 1, G404-G411.

39. Maule S, Tredici M, Dematteis A, et al. (2004) Postprandial hypotension treated with acarbose in a patient with type 1 diabetes mellitus. Clin Auton Res 14, 405-407.
40. Marco J, Valverde I, Faloona GR, et al. (1970) Endogenous gut glucagon-like immunoreactivity (GLI) and insulin secretion. Diabetologia 6, 630.

41. Khoo J, Rayner CK, Jones KL, et al. (2009) Incretin-based therapies: new treatments for type 2 diabetes in the new millennium. Ther Clin Risk Manag 5, 683-698.

42. Deane AM, Nguyen NQ, Stevens JE, et al. (2010) Endogenous glucagon-like peptide-1 slows gastric emptying in healthy subjects, attenuating postprandial glycemia. J Clin Endocrinol Metab 95, 215-221.

43. Schvarcz E, Palmer M, Aman J, et al. (1997) Physiological hyperglycemia slows gastric emptying in normal subjects and patients with insulin-dependent diabetes mellitus. Gastroenterology 113, 60-66.

44. Shafer RB, Levine AS, Marlette JM, et al. (1987) Effects of xylitol on gastric emptying and food intake. Am J Clin Nutr 45, 744-747. 